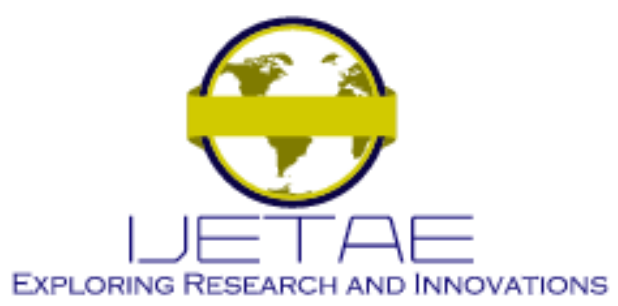

International Journal of Emerging Technology and Advanced Engineering

Website: www.ijetae.com (E-ISSN 2250-2459, Scopus Indexed, ISO 9001:2008 Certified Journal, Volume 11, Issue 08, August 2021)

Manuscript Received: 05 july 2021, Received in Revised form: 7 August 2021, Accepted: 12 August 2021

DOI: 10.46338/ijetae0821_06

\title{
Prototype of New Reliable Airport Luggage Tracker System
}

\author{
Dr. Omar Khattab ${ }^{1}$, Aljazi Almetlaqem ${ }^{2}$, Danah Almutairi ${ }^{3}$, Maryam Alnaser ${ }^{4}$, Maryam Almutairi ${ }^{5}$ \\ Department of Computer Science and Engineering, Kuwait College of Science and Technology (KCST), Kuwait
}

\begin{abstract}
Nowadays, the complaints of air passengers about mishandling of luggage are highly noticeable, where the number of passengers are on the increased. In this respect, several research works have been conducted using different technologies, such as Radio Frequency Identification (RFID), Global Positioning System (GPS), Global System for Mobile Communication (GPS), mobile applications, smart watches and QR code. However, none of them safely and effectively considers reclaiming passengers' belongings from the airport baggage handling carousel without the need for human intervention, which in turn increases the number of mishandled bags. Therefore, in this paper we propose a new Airport Luggage Tracker System (ALTS) in order to provide a reliable solution compared with the research works found in the literature. A prototype system based on the proposed design is successfully implemented and tested using Arduino UNO, RFID technology and website application (check-in and check-out at departure lounge and arrival lounge, respectively).
\end{abstract}

Keywords - radio frequency identification (RFID), tracking system (TS), airport luggage tracker system (ALTS).

\section{INTRODUCTION}

Although the airline industry claims that the number of lost luggage has been decreased using tracking technologies, tens of millions of bags still get lost frequently [1]. For example, statistics have been reported by the SITA (world's leading specialist in air transport communications and IT) that the total number of mishandled bags has approached to 24.8 million in 2018 , accounting for approximately 40 bags disappearing every minute [2].

The RFID is used in different applications [3] to automatically identify and track the location of objects such as passengers' luggage. It transfers and secures a useful data for operational analysis and planning [2]. The SITA and IATA (International Air Transport Association) have reported that the RFID could decrease the number of mishandled bags by an extra $25 \%$ by 2020 besides it could save the air transport industry $\$ 3$ billion in baggage mishandling costs [4]. According to IATA, the RFID shows a significant accuracy of $99.98 \%$ compared to barcodes alone [4].
There are many reasons for incidents of global baggage mishandling [5]:

- Someone taken the wrong bag.

- Luggage get stolen or lost.

- The airports using different technologies.

- Short connecting times between flights.

- Different luggage handling companies at airports.

- Flight delays and cancellations.

In this paper we therefore propose a reliable prototype of Airport Luggage Tracker System (ALTS) in order to reduce the number of mishandled bags compared with the research works found in the literature. The ALTS prototype effectively helps the airport administration to track the passengers' bags upon arrival to the airport baggage handling carousel without the need for human intervention, where tags on the passengers' bags and their passports are attached. It is successfully implemented and tested using Arduino UNO, RFID technology and website application (check-in and check-out at departure lounge and arrival lounge, respectively).

The rest of the paper is organized as follows: Section II presents related works of the airport tracker systems. A design of proposed ALTS is presented in section III. Implementation and testing of the proposed ALTS are presented in section IV. A discussion is presented in section V. A conclusion is presented in section VI. Finally, a future scope is presented in section VII.

\section{RELATED WORKS}

In this paper we have surveyed six recent research works which implemented for luggage tracking system and used different technologies [6-11]. In [6] the authors used the RFID technology where it has Low frequency RFID reader. In [7] the authors used mobile applications, smart watches and QR code. The drawbacks are: QR code is vulnerable to be destroyed, power consumption and impractical when wireless network is out of coverage.

In [8] the authors used the RFID, GSM and GPS modules where it does not consider passenger information. In [9] the authors used the RFID based bracelet and GSM module. 


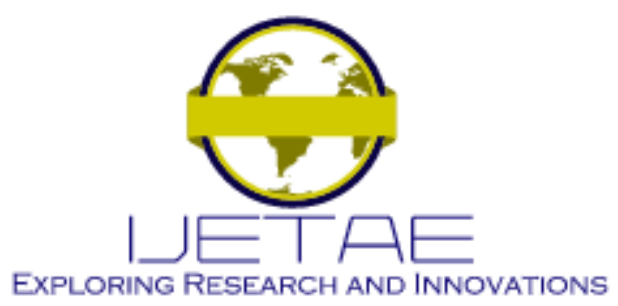

International Journal of Emerging Technology and Advanced Engineering

Website: www.ijetae.com (E-ISSN 2250-2459, Scopus Indexed, ISO 9001:2008 Certified Journal, Volume 11, Issue 08, August 2021)

The drawbacks are: bracelet is vulnerable to be destroyed and data can be lost. In [10] the authors used the GSM and GPS modules where it does not consider passenger information. In [11] the authors used ARDUINO UNO, GSM and GPS modules where it does not work if a phone is out of battery.

\section{The Design Of Proposed ALTS}

In Section II, six recent research works for luggage tracking system have been considered [6-11]. We offer a fair comparison between them, in terms of technology, consideration, drawbacks and cost. This is shown in Table I. It has been noticed from Table I that although the proposed research works used different technologies for luggage tracking system, they have had their own drawbacks and have not safely and effectively considered reclaiming passengers' belongings from the airport baggage handling carousel without the need for human intervention. We therefore come up with a reliable system in order to address these drawbacks and reduce the number of mishandled bags. The ALTS has two main scenarios: check-in (departure lounge) and check-out (arrival lounge), as shown in Fig. 1.

\section{A. Check-in}

Record the passenger's personal information, where every passenger gets a serial number (RFID medal for every passenger) linked with his/her bags (RFID card for each bag).

\section{B. Check-out}

Reduce the number of mishandled bags by checking the passenger's RFID medal which is linked with RFID cards.

\section{The Implementation And Testing Of The PROPOSED ALTS}

A prototype of ALTS has been successfully implemented and tested for different scenarios. Fig. 2 shows the used hardware:

- Arduino UNO: is a microcontroller board based on the ATmega328P.

- RFID Reader: RC522 RFID card reader module.

- RFID Tag.

- RFID Card.

- LCD: I2C communication interface with 4 pins: VCC, GND, SDA and SCL.

- Battery: 9v connected to Arduino with cap.

- Switch on/off: used for turning on/off the circuit.

- Push button: used to change the LCD display.

- LED: used to indicate that the circuit is on.

List of the used software is shown below:

- HTML \& CSS for design.

- PHP \& JavaScript for backend.

- SQL for database.

- Xampp server: used to test the website on the computer before it's uploaded to the internet.

TABLE I

A Fair Comparison of the Airport Tracker Systems

\begin{tabular}{|c|c|c|c|c|c|c|}
\hline Comparison & [6] & [7] & [8] & [9] & {$[10]$} & [11] \\
\hline Technology & RFID & $\begin{array}{l}\text { Mobile applications, smart } \\
\text { watches and QR code }\end{array}$ & $\begin{array}{l}\text { RFID, GSM and } \\
\text { GPS modules }\end{array}$ & $\begin{array}{l}\text { RFID based } \\
\text { bracelet and } \\
\text { GSM module }\end{array}$ & $\begin{array}{l}\text { GSM and } \\
\text { GPS modules }\end{array}$ & $\begin{array}{c}\text { ARDUINO UNO, } \\
\text { GSM and GPS } \\
\text { modules }\end{array}$ \\
\hline Consideration & Airport & Airport & Airport & Airport & Airport & Airport \\
\hline \multirow[b]{2}{*}{ Drawbacks } & \multicolumn{6}{|c|}{$\begin{array}{l}\text { They do not safely and effectively consider reclaiming passengers' belongings from the airport baggage handling carousel without the } \\
\text { need for human intervention }\end{array}$} \\
\hline & $\begin{array}{c}\text { Low } \\
\text { frequency } \\
\text { RFID reader }\end{array}$ & $\begin{array}{l}\text { QR code is vulnerable to be } \\
\text { destroyed, power consumption } \\
\text { and impractical when wireless } \\
\text { network is out of coverage }\end{array}$ & $\begin{array}{l}\text { Does not consider } \\
\text { passenger } \\
\text { information }\end{array}$ & $\begin{array}{l}\text { Bracelet is } \\
\text { vulnerable to be } \\
\text { destroyed and } \\
\text { data can be lost }\end{array}$ & $\begin{array}{l}\text { Does not } \\
\text { consider } \\
\text { passenger } \\
\text { information }\end{array}$ & $\begin{array}{l}\text { Does not work if a } \\
\text { phone is out of } \\
\text { battery }\end{array}$ \\
\hline Cost & Low & High & Medium & High & Medium & Medium \\
\hline
\end{tabular}




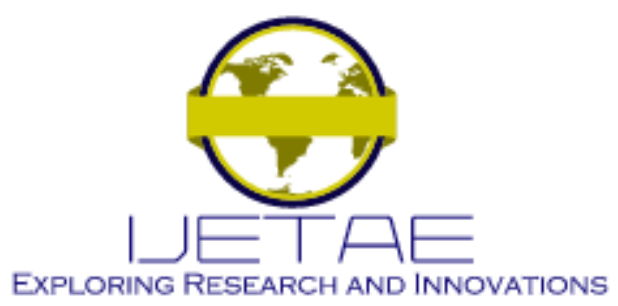

International Journal of Emerging Technology and Advanced Engineering

Website: www.ijetae.com (E-ISSN 2250-2459, Scopus Indexed, ISO 9001:2008 Certified Journal, Volume 11, Issue 08, August 2021)

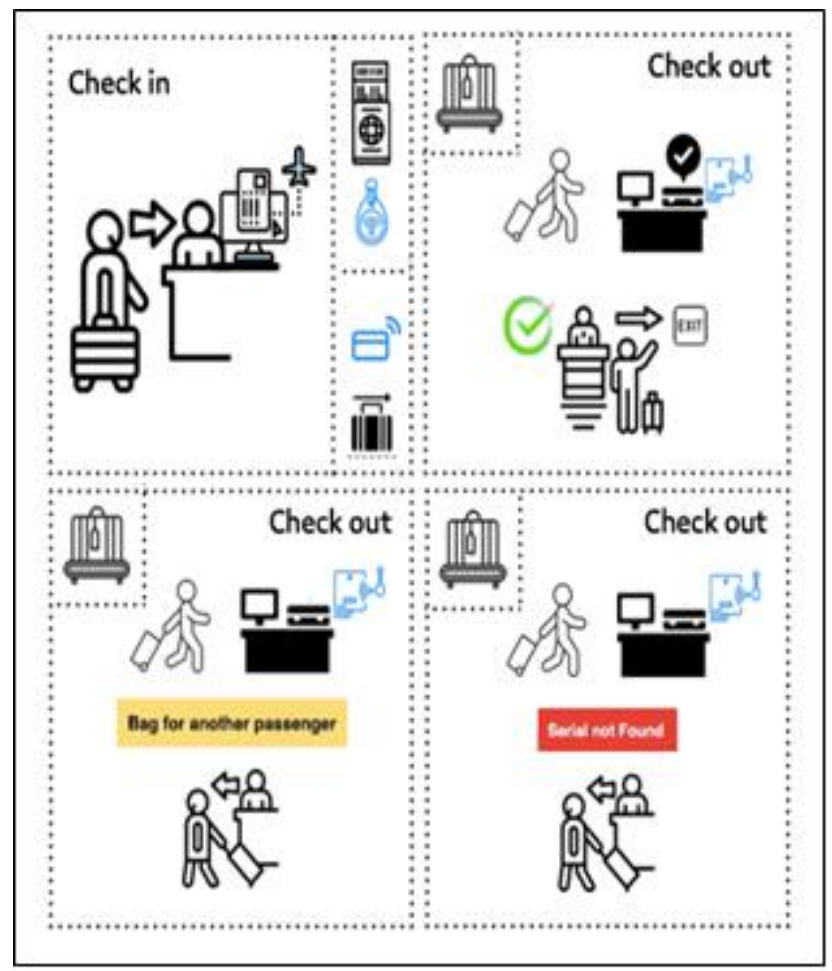

Figure 1. ALTS Scenarios

A. Check-in
- The passenger hands passport and ticket to the checkin officer.

- The check-in officer provides RFID medal (unique serial number) designed for every single passenger. In this scenario the serial number for the RFID medal is 134120.

- The check-in officer fills the passenger's personal information, the number, weight and colors of his/her bags, where each bag has its own RFID card (unique serial number) and it is hanged along with the bag. In this scenario we have four bags' serial numbers: 2231 , 4352, 1324 and 6654.

\section{B. Check-out}

There are four main steps, as shown in Fig. 4:

- The passenger proceeds to the luggage handling carousel to reclaim his/her bags.

- The passenger hands passport, ticket and RFID medal to the check-out officer, where the RFID

- medal is scanned to get passenger's serial number, which is used to show his/her information.

- The check-out officer checks the passenger's bags using RFID card. In this scenario, we assume that the passenger reclaims three bags duly (1324, 2231, 4352) and one wrongly (7641). The passenger therefore is required to reclaim the right bag (6654) in order to proceed in checking-out.

There are three main steps, as shown in Fig. 3:

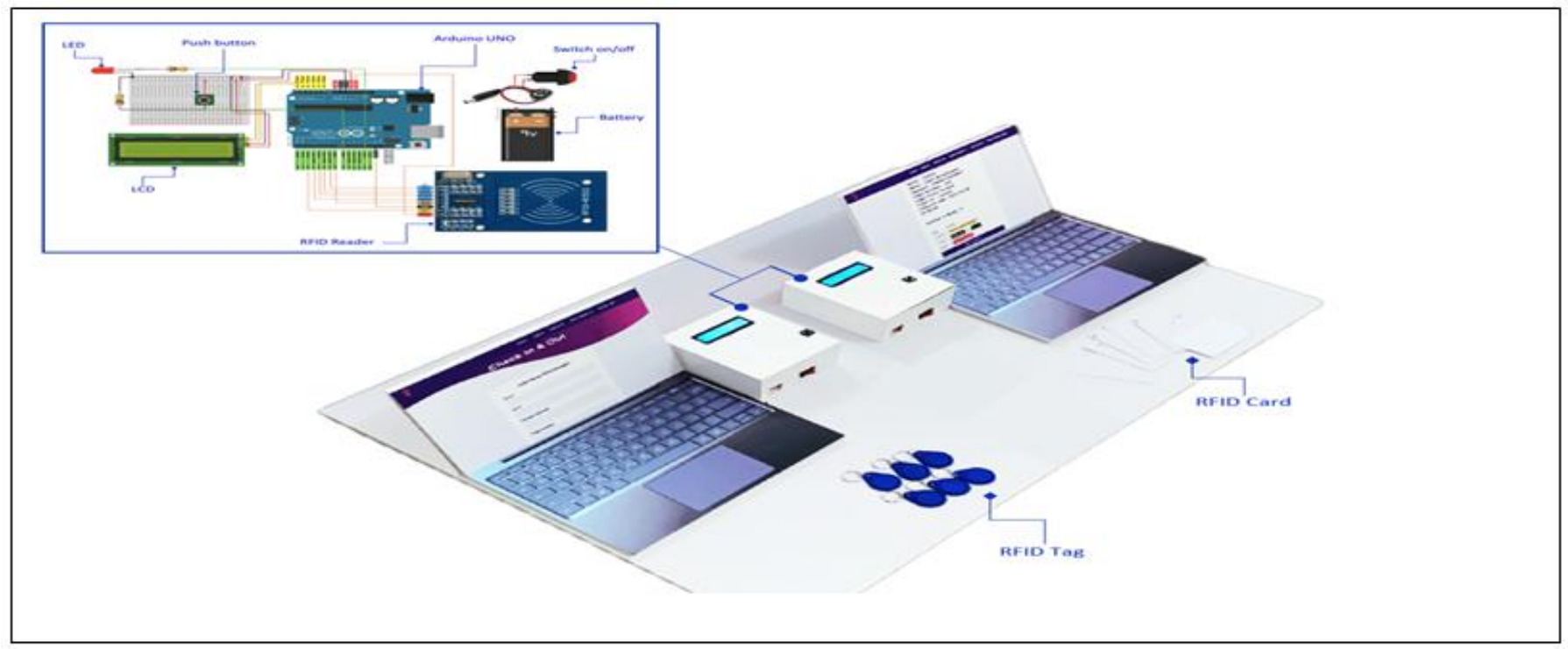

Figure 2. ALTS Hardware 


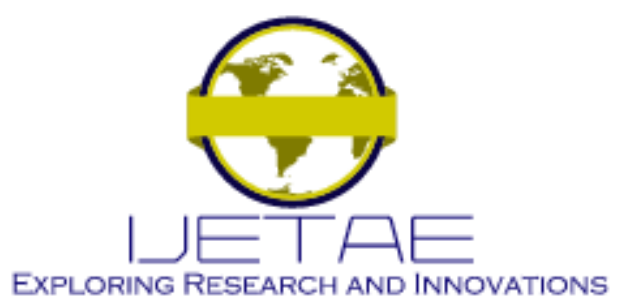

International Journal of Emerging Technology and Advanced Engineering

Website: www.ijetae.com (E-ISSN 2250-2459, Scopus Indexed, ISO 9001:2008 Certified Journal, Volume 11, Issue 08, August 2021)
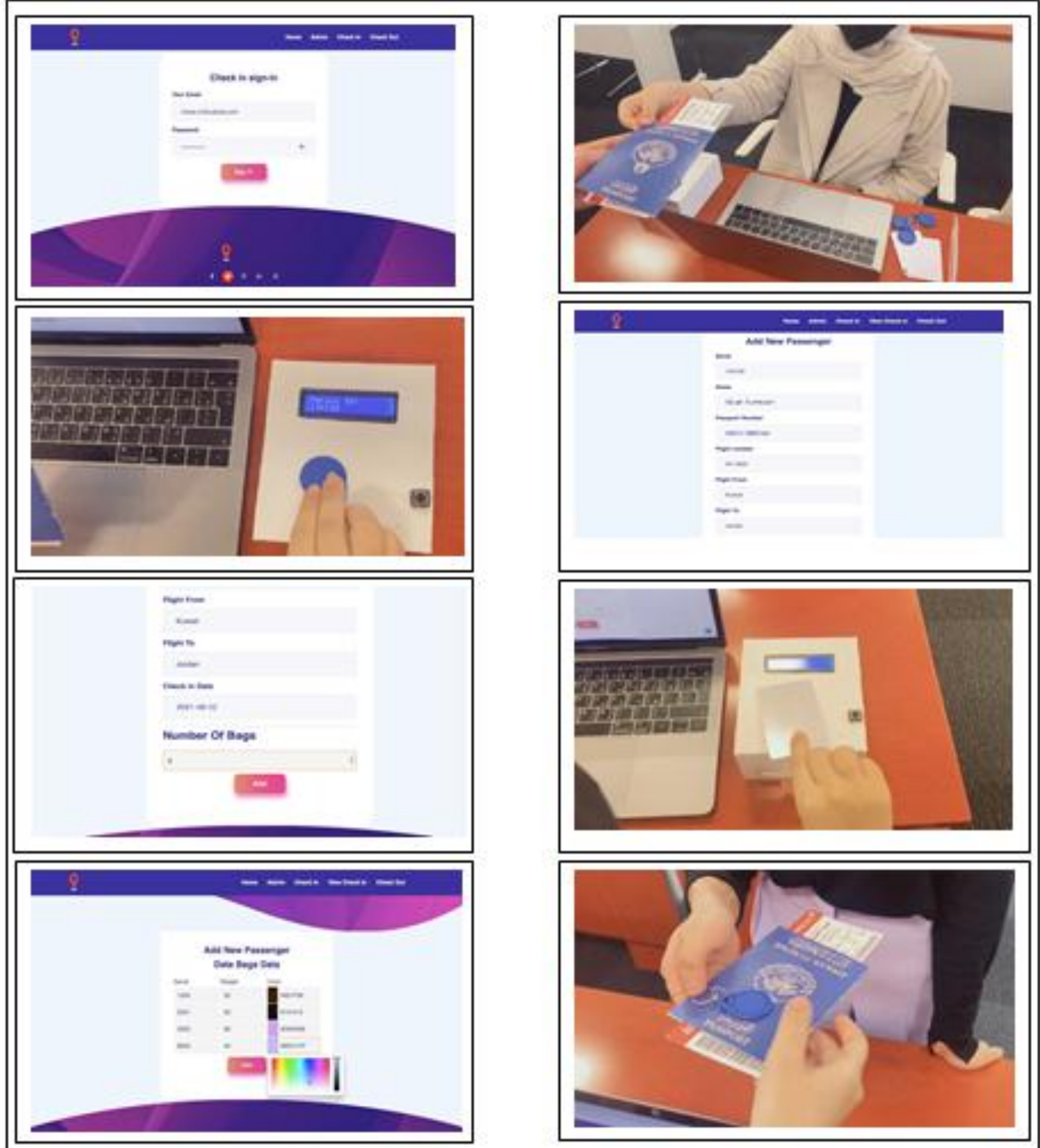

Figure 3. Check-in 


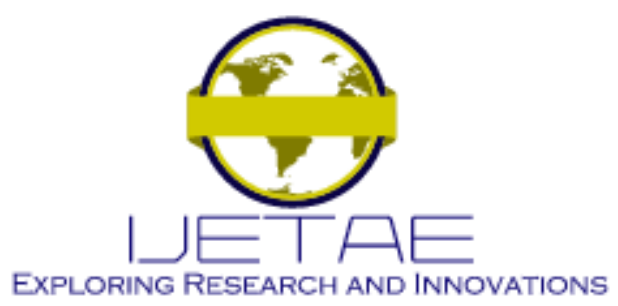

International Journal of Emerging Technology and Advanced Engineering

Website: www.ijetae.com (E-ISSN 2250-2459, Scopus Indexed, ISO 9001:2008 Certified Journal, Volume 11, Issue 08, August 2021)
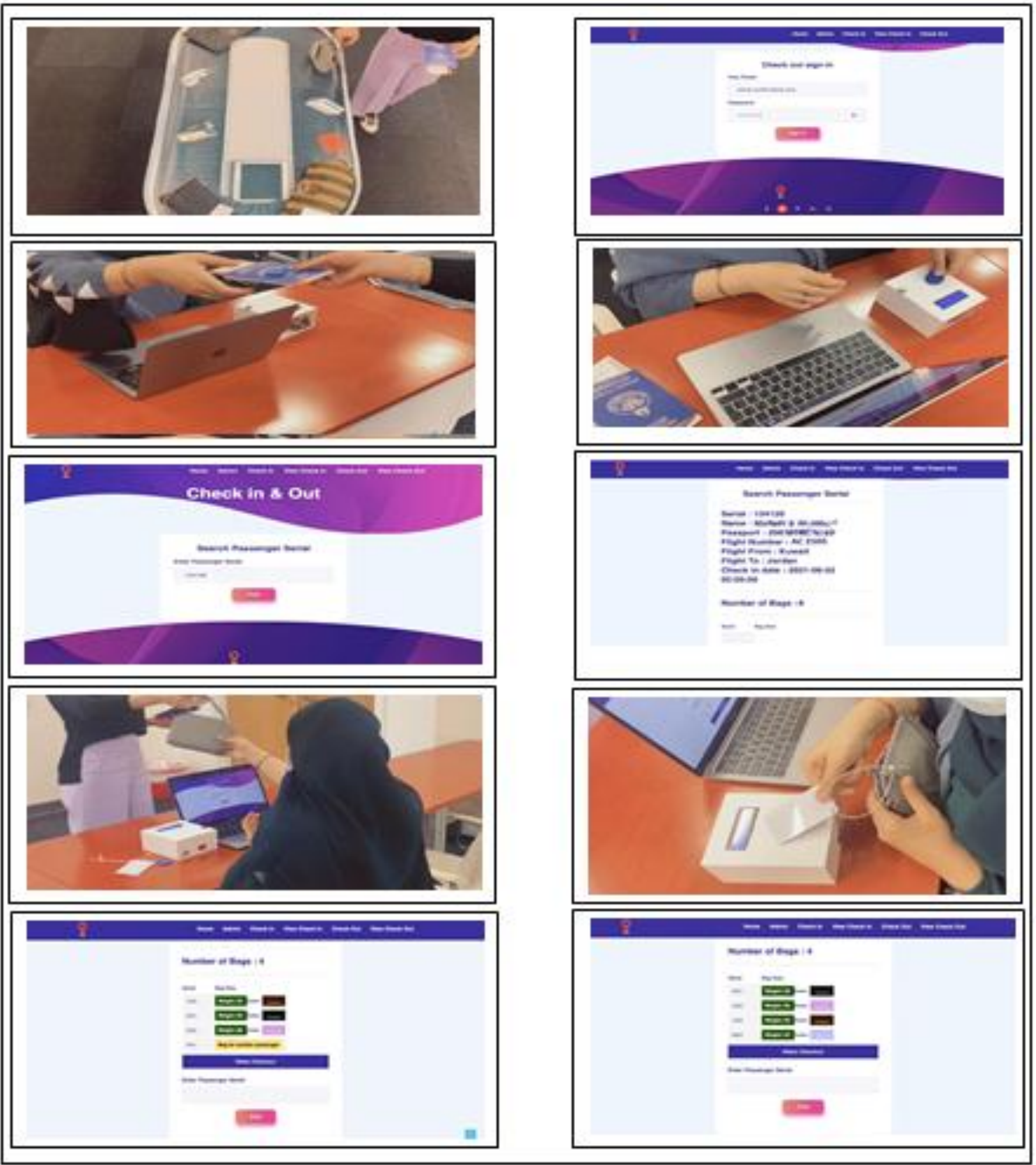

Figure. 4. Check-out 


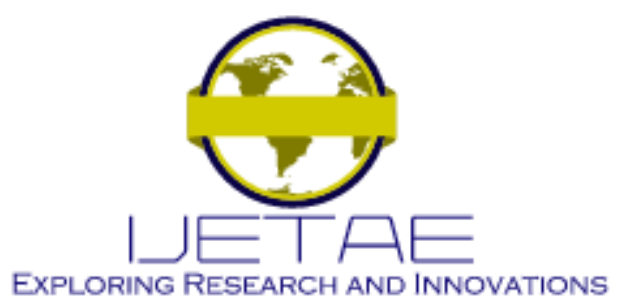

\section{International Journal of Emerging Technology and Advanced Engineering}

Website: www.ijetae.com (E-ISSN 2250-2459, Scopus Indexed, ISO 9001:2008 Certified Journal, Volume 11, Issue 08, August 2021)

\section{DISCUSSION}

The goal of the ALTS is to be executed fully functioning in terms of hardware and software. We have fulfilled these conditions through implementing and testing the prototype of the ALTS, which have proved effectiveness of the selected software and hardware components. This is obviously helps the passengers in efficiently reclaiming their belongings from the airport baggage handling carousel without the need for human intervention, which in turn reduces the number of mishandled bags.

It has been tested that the ALTS has accurately functioned the two main scenarios: check-in (departure lounge) and check-out (arrival lounge). A prototype of ALTS is shown in Fig. 5.

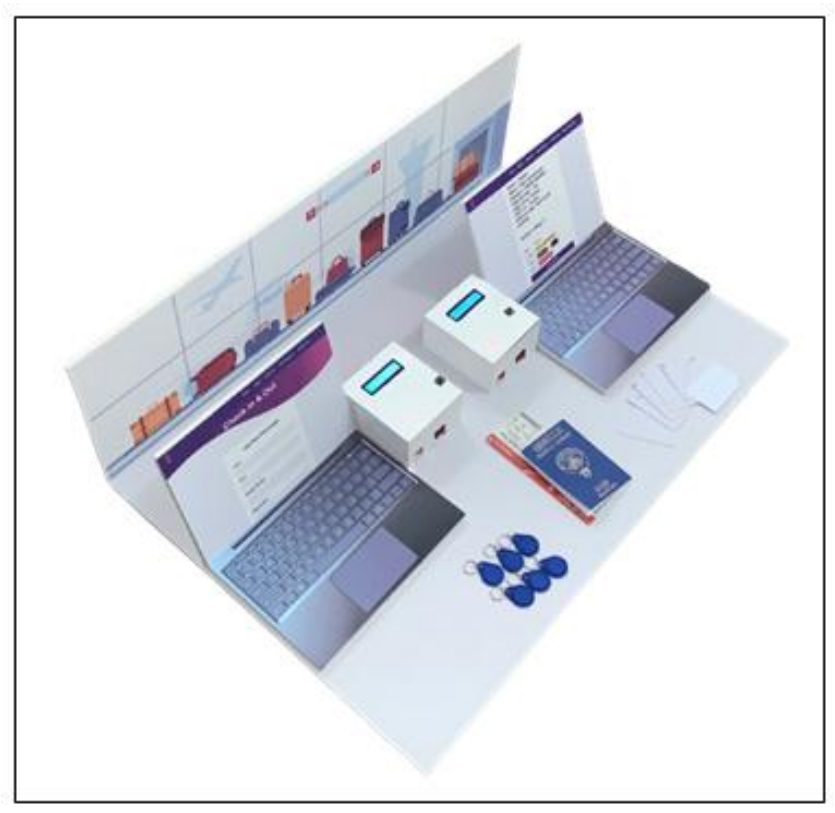

Figure. 5. ALTS Prototype

\section{CONCLUSION}

In the literature, several proposed research works were conducted and used different technologies for luggage tracking system such as RFID, GPS, GPS, mobile applications, smart watches and QR code. However, they have experienced some drawbacks and have not safely and effectively considered reclaiming passengers' belongings from the airport baggage handling carousel without the need for human intervention.
To address these issues, a reliable prototype system based on the proposed ALTS has been successfully implemented and tested.

\section{FUTURE SCOPE}

This ALTS could be developed to be a comprehensive solution in tracking passengers' bags taking into account all potential incidents of global baggage mishandling.

\section{REFERENCES}

[1] Why do airlines still mislay 25 million bags a year?, Available online: https://www.bbc.com/news/business-48437262, Accessed on 8 June, 2021.

[2] Solving the carousel crisis: How technology can make luggage safer?, Available online: https://www.airporttechnology.com/features/baggage-tracking-technology-for-airports/, Accessed on 8 June, 2021.

[3] O. Khattab, H. Matbaqi, H. Dashti and R. Abdullah, A Market Research Study on a Peer-to-Peer Network, International Journal of Advanced Trends in Computer Science and Engineering, 9(5) (2020) ,87-90.

[4] IATA commits to improve baggage handling through RFID and realtime tracking, Available online: https://www.futuretravelexperience.com/2019/06/iata-improvebaggage-handling-rfid-technology/, Accessed on 8 June, 2021.

[5] Why and how do airlines misplace or lose your luggage in 2019?, Available online: https://www.flightdelayed.com/blog/2019/08/29/why-and-how-do-airlines-misplaceor-lose-your-luggage-in-2019, Accessed on 8 June, 2021.

[6] A. Kavianpour, R. Monterrosa and R. Badran, Automated luggage tracking system, American Society For Engineering Education, (2010), AC 2010-679.

[7] A. Slassi, S. Asmae, B. Yassine and S. Alj, An interactive RFIDbased Bracelet for Airport luggage tracking system, International Conference on Intelligent System, Modelling and Simulation, IEEE, (2013), 2166-0662/13.

[8] K. Vanitha, C. Jeevitha and D. Kavin, Airport luggage tracking system using RFID technology, International Journal of Advanced Research in Biology Engineering Science and Technology (UARBEST), 2(10) (2016), 937 - 942.

[9] N. Koteswaramma, P.A. Harsha and K. Divya, FPGA based tracking system in airport, 9th International Conference on Recent Innovations in Science, Engineering and Management (RIESM-17), (2017).

[10] V. Gupta, R. Kumar, R. Mishra, S. Sivach and A. Senwal, Design and Optimization of Luggage Tracking System on Airport, Proceeding of International Conference on Intelligent Communication, Control and Devices, (2016), 833-838.

[11] R. Chaturvedi, K. Darji, A. Mahajan and M. Varghese, Real Time Airport Luggage Tracking System, International Conference on Smart City and Emerging Technology (ICSCET), (2018), 1-5. 